\title{
Grand challenges in biomaterials
}

\author{
Hasan Uludağ * \\ University of Alberta, Edmonton, $A B$, Canada \\ *Correspondence: hasan.uludag@ualberta.ca \\ Edited by: \\ Aldo Ferrari, ETH Zürich - Eidgenössische Technische Hochschule Zürich, Switzerland \\ Reviewed by: \\ Claudio G. Rolli, Weizmann Institute of Science, Israel
}

Keywords: biomaterials, regeneration, molecular design, biomimicry, biocompatibility

The biomaterials field constitutes a transdisciplinary activity in which synthetic or naturally derived materials are utilized for a variety of desired outcomes in living systems. Biomaterials may act as physical supports at times, providing a space in which biological systems manifest their inherent characteristics. More commonly, biomaterials actively participate in the performance of a biological system, supporting or even inducing desirable traits that would have not been possible without the biomaterial. While biomaterials have become an integral part of several industrial processes and products, it is their medical use in the body that fascinated and stimulated our imagination. From simple entrapment of enzymes (Chang, 1964), we witnessed the creation of "bioartificial" organs combining cells and materials (Chick et al., 1977), followed by enzyme-sensitive biomaterials by design (Ulbrich et al., 1980), and engineered materials that matched the physical (Urry et al., 1981) and cellular requirements (Massia and Hubbell, 1991) of injured tissues. We learned to utilize biomaterials to control the release of small molecules such as drugs (Schwartz et al., 1968; Goodman and Banker, 1970) and especially macromolecules such as proteins (Langer and Folkman, 1976), which stimulated us to explore unique therapies. The potential of biomaterials is manifested in diverse areas and every organ in our bodies have benefited from them in one form or another. To fulfill such a broad translational promise, one needs to rely on sound scientific and engineering practice and should be exceptionally vigilant in fabricating and assessing the constructed systems. Identifying a few unifying (fundamental) principles for developing functional biomaterials is difficult when the biomaterials are intended for so many different uses, whether to stimulate our body's surveillance system to fight malignant cells or infections, to restore the physical barrier in skin upon losing its integrity, or to act as a blood conduit in tiny channels. I believe that the challenges facing functional biomaterials need to be addressed in the context of intended applications. However, I would like to propose that one should be mindful of two broad challenges irrespective of the specific utility of the biomaterials:

\section{DOING G00D: EFFICACY}

New biomaterials give us a wonderful opportunity to do good and improve the status quo. It might be possible to probe previously explored phenomena in a new way and reveal hidden new phenomena due to deployment of novel functional biomaterials (McIntyre et al., 2004). We might accelerate or enable healing that was not previously possible when we combine interactive biomaterials (Hubbell, 1995) and potent inducers (Wozney et al., 1988). Such beneficial outcomes might be possible because biomaterials, when developed in the right way, have the potential to domesticate the nature, that is, to prevent its detrimental aspects from taking over an injury while enabling native processes to undertake the healing activity. This should excite the practitioners in the field, while energizing the scientist, the engineer, and the clinician to amalgamate their knowhow and come up with creative solutions. The collective wisdom in the field can foster us to come up with creative solutions to our problems. These solutions may come from simply borrowing ideas from other fields and making use of biomaterials in a way that was not previously imagined, such as the idea of "printing" biological matter (Giordano et al., 1996).
Alternatively, we might have to rely on novel chemical approaches to come up with totally synthetic or semi-synthetic materials with unique features and properties (Lee et al., 2005; Verheyen et al., 2011). Endogenous chemicals and architectures can guide new biomaterials for previously unforeseen applications. While nature can guide us toward uniquely beneficial features, we could come up with features un-matched in nature. We might have to explore physical means of creating our functional materials from "self" or "forced" assemblies (Chen et al., 2014), or rely on biological systems to obtain synthetic biomaterials that could not be envisioned before (Khalil and Collins, 2010; Leszczak et al., 2014). For the latter, one can envision cellular factories genetically engineered to synthesize, assemble, and deposit complex materials ready for tissue regeneration. Advanced computational techniques will need to be employed to better understand a regeneration process induced by biomaterials (Mousavi et al., 2013) or gene delivery systems (Meneksedag-Erol et al., 2014), with the intention of improving the design of biomaterials. Temporal and spatial information could be obtained with computational tools that are not readily available by current experimental approaches, such as the molecular basis for effective organization of self-assembling building blocks. Doing good, however, needs to be undertaken expeditiously and in the context of financial and ethical pressures facing our society. We do not have the luxury of working at a leisurely pace while the society is expecting cost-effective solutions to partially met or unmet clinical problems. This can be achieved by relying on innovative biomaterials that are functional at molecular level, fabricated devices that are exquisitely designed and engineered at the 
nano-micro-meso scale and assessed comprehensively in relevant biological systems. Let there be no doubt that we can ask our biomaterials to jump higher and run faster while saving lives and reducing our financial burden.

\section{DOING NO-HARM: SAFETY}

One cannot overestimate the unpredictable nature of living systems and their ability to adopt and respond in the face of an intrusion. Nature has a way of reminding us of the limitations of our good intentions, whether we attempt to maintain our circulation with artificial devices (clotting problem; Nosé et al., 1967), or deliver a gene to support a failing physiology (genotoxicity; Hacein-Bey-Abina et al., 2003). We need to minimize or preferably eliminate the adverse impact of biomaterials on biological systems. This calls for using naturally existing materials that can participate in endogenous processes of metabolism and elimination, or rely on building blocks that are harmless to biological systems. We need to keep a focus on different scales of biological systems when attempting to do noharm; the molecular scale where perturbations of native biomolecular structures need to be avoided, the cellular scale where adverse effects manifest themselves as a result of physical alterations in sub-cellular structures, tissue/organ scales where the special anatomical structures, such as the junctional alignment of cells or tubular arrangement of blood vessels, should not be compromised. These considerations are amplified especially when we create designer topographies or nano-structured materials (Shvedova and Kagan, 2010, Koegler et al., 2012). The best way to ensure "no-harm" is to rely on degradable biomaterials that leave no traces of the biomaterial behind after the biomaterial completes its task in the body (Bianco et al., 2011; Dürig et al., 2011), and with degradation products that are either excreted directly or can enter into natural metabolic pathways. One cannot take a narrow approach to safety; a complementary analysis of body fluids, immune, and other surveillance systems have to be vigilantly probed to ensure biomaterial compliance with the biological system in the short term. Given the possibility of altering the expression of a wide range of genes whenever a therapeutic agent is introduced into the body, long-term assessments for genotoxicity of the biomaterials will be needed. At the end of the day, we should be on guard to expect a surprise from the nature, but also be confident that progress will be made by overcoming the presented obstacles. Preclinical models, designed for the intended application [after all, "biocompatibility" is inherently linked to an application (Williams, 2008)] and characterized thoroughly, are our best tools to pursue no-harm before the biomaterials find their way to clinical utility (Byrom et al., 2010; Muschler et al., 2010; Fitzgerald et al., 2011).

\section{FUTURE OF BIOMATERIALS}

While we focus on doing good and ensuring no-harm, it is clear to me that our challenges are closely tied to the problems that we are attempting to solve. This makes it difficult to focus on a few overarching or grand challenges, which thinly disperses our collective wisdom throughout the field. However, I believe that it is still possible to identify several fundamental challenges that are critical to the biomaterials field and can lead to quantum leaps.

\section{EMULATING NATURE FOR NEW MATERIALS WITH UNIQUE FUNCTIONALITIES}

Nature has given us materials that display the highest strength, strongest adhesion, greatest flexibility, error-free duplication, induced degradation, and unique on-demand features, to name a few qualities. While we are learning to mimic nature to reach its level of sophistication with synthetic biomaterials, we might even do better than what we are emulating when we apply our ingenuity and tools fully. Super-adhesive biomaterials (Brubaker and Messersmith, 2012), for example, might one day seal vascular defects at a fraction of the time that is possible today after simply injecting the biomaterials in the circulatory system. Artificial cells (Forster and Church, 2006), whose development was put aside in favor of native cells, might be deployed in the fight against cancer in the future. An indepth understanding of natural materials, especially their operational principles, is paramount in this endeavor.

\section{CONTROLLING THE ORGANIZATION OF MATTER}

Desired outcomes from biomaterials are closely related to the organization of their building blocks. For some applications, organization at atomic scale is paramount, while other applications may call for organization at a specific region of the nanoor micro-scale. By assembly of right building blocks of a biomaterial at the appropriate scale, and then employing an engineered and controllable fabrication process for a functional device, we should be able to fulfill the promise of the biomaterials more fully. Creating nanoparticles with the ability to self-propel and move toward, a chemo-attractant might be feasible with structures that are assembled from functionally organized domains. Given the inherent difficulties of fabricating structurally controlled materials and devices for the first time, computational approaches could be a good start for exploring hypothetical scenarios for the organized matter.

\section{DESIGNING THE INTERFACE BETWEEN BIOMATERIALS AND BIOLOGICAL SYSTEMS TO MODULATE RESPONSES}

It is well recognized that biomaterial surfaces are distinctly different from their bulk features, be it their chemical composition or physical properties. We should deliberately control the surface features of biomaterials since all biological systems first get exposed and subsequently respond to this interface. For example, it may be possible to create sensors that function endlessly due to "stealth" surface features that make the body ignore their presence while they sense the immediate environment. We might have to induce "tolerance" to biomaterials for a stable, non-reactive interface, reminiscent of tissue transplantation (Bishop et al., 2011). For reactive interfaces intended to interact with their surroundings, the challenge of presenting biological cues in a sea of adverse host factors (proteolytic enzymes, protein adsorption, extracellular matrix deposition, etc.) remains to be addressed. Will it be possible to design biomaterials in such a way to target the right cellular process for an amplified/stable response, while the body is attempting to isolate or neutralize the foreign entity?

\section{RELYING ON INHERENT PHYSIOLOGICAL MECHANISMS}

We routinely relied on biostable materials for permanent solutions at a time when little was known about the inherent capacity of our bodies to respond to undesired 
circumstances. With rapidly accumulating information on molecular and cellular basis of pathophysiology and regeneration, time is ripe to rely on our inherent capabilities for healing, and biomaterials can be designed to take advantage of innate processes to repair failing tissues and organs. While this approach is beginning to fulfill its promise in certain cases, such as the bone and skin, its real return will be in the repair of vital organs that evaded regenerative healing, such as heart and brain. We will need to employ our entire arsenal in this regard to attract the right cells, control the fate of invading cells, be it morphogenetic differentiation, senescence, or apoptosis, while the host response to our intervention supports the intended outcome. Controlling the mechanical features of functional devices will be equally important in this endeavor due to their impact on cellular fate (Engler et al., 2006). How mechano-regulation can be implemented at a wound site, and not just under culture conditions, will be an important goal to achieve. Biomaterial scaffolds designed in the right way will play a significant role in this endeavor.

\section{IMPROVING OVER “GOLD" STANDARD}

Our biomaterials, once fabricated into functional devices, should do better than the accepted practice when it comes to efficacy, side-effects, and costs; the expectation is to improve in all three aspects. Innovative fabrication technologies capable of handling multimodal biomaterials and other biological materials, such as regulatory molecules and cells, will be required to achieve this goal. Simpleto-produce DNA delivery systems functioning better than viruses, "off-the-shelf" kidneys for transplantation or artificial cells secreting insulin on-demand, produced by large-scale cost-effective manufacturing processes, might 1 day find their way to medical practice. Of course, strategies to prevent opportunistic infections are expected to be an integral part of each intervention. Disruptive discoveries will play a key role in setting up new gold standards. Knowing that induced pluripotent cells (Takahashi and Yamanaka, 2006) can one day shake up the foundation of tissue engineered devices, and microRNA can add a new dimension into regenerative medicine (Lee et al., 1993), we should not shy away from unsettling ideas and seek opportunities to actively incorporate such ideas into our practice. The best way to ensure improved gold standards is to engage clinicians in biomaterials development and overcome the challenges of cooperating across disciplines whose foci are varied.

We expect the studies published in the specialty section of Biomaterials, under Frontiers in Bioengineering and Biotechnology and Materials, to contribute to solving our current challenges, while defining new challenges for the future.

\section{ACKNOWLEDGMENTS}

The biomaterials activity in the Author's lab was supported by numerous granting agencies in the past, including NSERC, CIHR, CFI, Whitaker Foundation, AIHS (formerly AHFMR), Canadian Breast Cancer Foundation, U. of Alberta, AITF, AB Cancer Foundation, as well as private companies. We are mindful of the limited space allocated to this article and the omission of critical contributions from many scientists and engineers, for which I deeply apologize. I thank the following colleagues at the University of Alberta for critical comments on the manuscript: Dr. Tian Tang (Department of Mechanical Engineering, Faculty of Engineering), Dr. Afsaneh Lavasanifar (Faculty of Pharmacy and Pharmaceutical Sciences), Dr. Adetola Adesida (Department of Surgery, Faculty of Medicine and Dentistry) and Dr. Nadr Jomha (Department of Surgery, Faculty of Medicine and Dentistry).

\section{REFERENCES}

Bianco, A., Kostarelos, K., and Prato, M. (2011). Making carbon nanotubes biocompatible and biodegradable. Chem. Commun. 47, 10182-10188. doi:10.1039/clcc13011k

Bishop, G. A., Ierino, F. L., Sharland, A. F., Hall, B. M., Alexander, S. I., Sandrin, M. S., et al. (2011). Approaching the promise of operational tolerance in clinical transplantation. Transplantation 91, 1065-1074. doi:10.1097/TP.0b013e318215e742

Brubaker, C. E., and Messersmith, P. B. (2012). The present and future of biologically inspired adhesive interfaces and materials. Langmuir 28, 2200-2205. doi:10.1021/la300044v

Byrom, M. J., Bannon, P. G., White, G. H., and Ng, M. K. (2010). Animal models for the assessment of novel vascular conduits. J. Vasc. Surg. 52, 176-195. doi:10.1016/j.jvs.2009.10.080

Chang, T. M. (1964). Semipermeable microcapsules. Science 146, 524-525. doi:10.1126/science. 146.3643 .524
Chen, A. Y., Deng, Z., Billings, A. N., Seker, U. O., Lu, M. Y., Citorik, R. J., et al. (2014). Synthesis and patterning of tunable multiscale materials with engineered cells. Nat. Mater. 13, 515-523. doi:10. 1038/nmat3912

Chick, W. L., Perna, J. J., Lauris, V., Low, D., Galletti, P. M., Panol, G., et al. (1977). Artificial pancreas using living beta cells: effects on glucose homeostasis in diabetic rats. Science 197, 780-782. doi:10.1126/science.407649

Dürig, J., Dührsen, U., Klein-Hitpass, L., Worm, J., Hansen, J. B., Ørum, H., et al. (2011). The novel antisense Bcl-2 inhibitor SPC2996 causes rapid leukemic cell clearance and immune activation in chronic lymphocytic leukemia. Leukemia 25, 638-647. doi:10.1038/leu.2010.322

Engler, A. J., Sen, S., Sweeney, H. L., and Discher, D. E. (2006). Matrix elasticity directs stem cell lineage specification. Cell 126, 677-689. doi:10.1016/j.cell. 2006.06.044

Fitzgerald, K. T., Holladay, C. A., McCarthy, C., Power, K. A., Pandit, A., and Gallagher, W. M. (2011). Standardization of models and methods used to assess nanoparticles in cardiovascular applications. Small 7, 705-717. doi:10.1002/smll.201001347

Forster, A. C., and Church, G. M. (2006). Towards synthesis of a minimal cell. Mol. Syst. Biol. 2, 45. doi:10.1038/msb4100090

Giordano, R. A., Wu, B. M., Borland, S. W., Cima, L. G., Sachs, E. M., and Cima, M. J. (1996). Mechanical properties of dense polylactic acid structures fabricated by three dimensional printing. J. Biomater. Sci. Polym. Ed. 8, 63-75. doi:10. 1163/156856297X00588

Goodman, H., and Banker, G. S. (1970). Molecularscale drug entrapment as a precise method of controlled drug release. I. Entrapment of cationic drugs by polymeric flocculation. J. Pharm. Sci. 59, 1131-1137. doi:10.1002/jps.2600590815

Hacein-Bey-Abina, S., Von Kalle, C., Schmidt, M., McCormack, M. P., Wulffraat, N., Leboulch, P., et al. (2003). LMO2-associated clonal T cell proliferation in two patients after gene therapy for SCID-X1. Science 302, 415-419. doi:10.1126/science.1088547 Erratum in: Science 302, 568,

Hubbell, J. A. (1995). Biomaterials in tissue engineering. Nat. Biotechnol. 13, 565-576. doi:10.1038/ nbt0695-565

Khalil, A. S., and Collins, J. J. (2010). Synthetic biology: applications come of age. Nat. Rev. Genet. 11, 367-379. doi:10.1038/nrg2775

Koegler, P., Clayton, A., Thissen, H., Santos, G. N., and Kingshott, P. (2012). The influence of nanostructured materials on biointerfacial interactions. Adv. Drug Deliv. Rev. 64, 1820-1839. doi:10.1016/j.addr. 2012.06.001

Langer, R., and Folkman, J. (1976). Polymers for the sustained release of proteins and other macromolecules. Nature 263, 797-800. doi:10. 1038/263797a0

Lee, C. C., MacKay, J. A., Fréchet, J. M., and Szoka, F. C. (2005). Designing dendrimers for biological applications. Nat. Biotechnol. 23, 1517-1526. doi: $10.1038 /$ nbt1171

Lee, R. C., Feinbaum, R. L., and Ambros, V. (1993). The C. elegans heterochronic gene lin-4 encodes small RNAs with antisense complementarity to lin14. Cell 75, 843-854. doi:10.1016/0092-8674(93) 90529-Y 
Leszczak, V., Place, L. W., Franz, N., Popat, K. C., and Kipper, M. J. (2014). Nanostructured biomaterials from electrospun demineralized bone matrix: a survey of processing and crosslinking strategies. ACS Appl. Mater. Interface 6, 9328-9337. doi:10. 1021/am501700e

Massia, S. P., and Hubbell, J. A. (1991). Human endothelial cell interactions with surface-coupled adhesion peptides on a nonadhesive glass substrate and two polymeric biomaterials. J. Biomed. Mater. Res. 25, 223-242. doi:10.1002/jbm. 820250209

McIntyre, J. O., Fingleton, B., Wells, K. S., Piston, D. W., Lynch, C. C., Gautam, S., et al. (2004). Development of a novel fluorogenic proteolytic beacon for in vivo detection and imaging of tumour-associated matrix metalloproteinase-7 activity. Biochem. J. 377, 617-628. doi:10.1042/BJ20030582

Meneksedag-Erol, D., Tang, T., and Uludağ, H. (2014). Molecular modeling of polynucleotide complexes. Biomaterials 35, 7068-7076. doi:10. 1016/j.biomaterials.2014.04.103

Mousavi, S. J., Doweidar, M. H., and Doblaré, M. (2013). 3D computational modelling of cell migration: a mechano-chemo-thermo-electrotaxis approach. J. Theor. Biol. 329, 64-73. doi:10.1016/j. jtbi.2013.03.021

Muschler, G. F., Raut, V. P., Patterson, T. E., Wenke, J. C., and Hollinger, J. O. (2010). The design and use of animal models for translational research in bone tissue engineering and regenerative medicine. Tissue Eng. B Rev. 16, 123-145. doi:10.1089/ten.TEB. 2009.0658
Nosé, Y., Kwan-Gett, C. S., Hino, K., Kolff, W. J., and Effler, D. B. (1967). Clot formation inside the artificial heart device. J. Thorac. Cardiovasc. Surg. 54, 697-706.

Schwartz, J. B., Simonelli, A. P., and Higuchi, W. I. (1968). Drug release from wax matrices. I. Analysis of data with first-order kinetics and with the diffusion-controlled model. J. Pharm. Sci. 57, 274-277. doi:10.1002/jps.2600570206

Shvedova, A. A., and Kagan, V. E. (2010). The role of nanotoxicology in realizing the 'helping without harm' paradigm of nanomedicine: lessons from studies of pulmonary effects of single-walled carbon nanotubes. J. Intern. Med. 267, 106-118. doi: 10.1111/j.1365-2796.2009.02188.x

Takahashi, K., and Yamanaka, S. (2006). Induction of pluripotent stem cells from mouse embryonic and adult fibroblast cultures by defined factors. Cell 126, 663-676. doi:10.1016/j.cell.2006.07.024

Ulbrich, K., Zacharieva, E. I., Obereigner, B., and Kopecek, J. (1980). Polymers containing enzymatically degradable bonds V. Hydrophilic polymers degradable by papain. Biomaterials 1, 199-204. doi:10.1016/0142-9612(80)90017-4

Urry, D. W., Harris, R. D., and Long, M. M. (1981) Compounding of elastin polypentapeptide to collagen analogue: a potential elastomeric prosthetic material. Biomater. Med. Dev. Artif. Organs 9, 181-194.

Verheyen, E., Schillemans, J. P., van Wijk, M., Demeniex, M. A., Hennink, W. E., and van Nostrum, C. F. (2011). Challenges for the effective molecular imprinting of proteins. Biomaterials
32,3008-3020. doi:10.1016/j.biomaterials.2011.01. 007

Williams, D. F. (2008). On the mechanisms of biocompatibility. Biomaterials 29, 2941-2953. doi:10.1016/ j.biomaterials.2008.04.023

Wozney, J. M., Rosen, V., Celeste, A. J., Mitsock, L. M., Whitters, M. J., Kriz, R. W., et al. (1988). Novel regulators of bone formation: molecular clones and activities. Science 242, 1528-1534. doi:10.1126/ science.3201241

Conflict of Interest Statement: The author declares that the research was conducted in the absence of any commercial or financial relationships that could be construed as a potential conflict of interest.

Received: 12 August 2014; accepted: 02 October 2014; published online: 17 October 2014.

Citation: Uludă̆ H (2014) Grand challenges in biomaterials. Front. Bioeng. Biotechnol. 2:43. doi: 10.3389/fbioe.2014.00043

This article was submitted to Biomaterials, a section of the journal Frontiers in Bioengineering and Biotechnology.

Copyright (c) 2014 Uludağ. This is an open-access article distributed under the terms of the Creative Commons Attribution License (CC BY). The use, distribution or reproduction in other forums is permitted, provided the original author(s) or licensor are credited and that the original publication in this journal is cited, in accordance with accepted academic practice. No use, distribution or reproduction is permitted which does not comply with these terms. 